\title{
Epidemic e a produção de afetos no cinema de Lars von Trier'
}

\author{
Emilia Valente Galvão²
}

1. Uma versão preliminar e reduzida deste trabalho foi apresentada durante o XVI Encontro Socine, realizado de 8 a 11 de outubro de 2012, em São Paulo.

2. Mestre e doutoranda em Comunicação e Cultura Contemporâneas pela UFBA, especialista em anãlise dos discursos audiovisuais pela mesma instituição. E-mail: emiliamariavalente@yahoo.com.br 


\section{Resumo}

O objetivo deste artigo é examinar elementos da obra do cineasta dinamarquês Lars von Trier, a partir das noções de participação afetiva (MORIN, 1971; METZ, 1977) e modos de produção de afetos (ODIN, 2000). Por meio da análise do filme Epidemic (1987), o texto tenta demonstrar como, desde o início de sua carreira, o diretor vem colocando em cena uma série de problemas relacionados à expressão dos afetos dos personagens e à convocação da experiência afetiva do espectador a partir da apropriação de estratégias associadas aos gêneros de corpo (WILLIAMS, 1991).

\section{Palavras-chave}

Lars von Trier, Epidemic, espectatorialidade cinematográfica, participação afetiva.

\section{Abstract}

This article aims to examine some aspects of the work of the Danish filmmaker Lars von Trier by means of the notions of affective participation and "modes of production of affects" (ODIN, 2000). Through an analysis of the film Epidemic (1987), the document tries to demonstrate how, since the beginning of his career, and by the appropriation of some strategies associated to film bodies (WILLIAMS, 1991), the director stresses several ethical and esthetical problems related to the expression of characters affective responses and the elicitation of spectators affective reactions.

\section{Keywords}

Lars von Trier, Epidemic, cinema spectatorship, affective participation. 
ano 2 número 4

Temáticas

Livres

\section{Introdução}

Na época do lançamento do filme Epidemic, em 1987, o dinamarquês Lars von Trier era um cineasta ainda pouco conhecido do grande público em nível internacional, mas já com algum prestigio no circuito de festivais. Três anos antes, seu primeiro longa-metragem de ficção, $O$ elemento do crime (Forbrydelsens element, 1984) havia sido contemplado com o prêmio técnico em Cannes e antes disso, outros filmes de curta e média metragem dirigidos por ele tinham sido premiados em festivais internacionais ${ }^{3}$. Epidemic, no entanto, não foi bem recebido na mostra Un certain regard do Festival de Cannes e teve um desempenho fraco de bilheteria, a ponto do diretor tornar-se "persona non grata no negócio do cinema dinamarquês" (LUMHOLDT, 2003, p. 22). Até hoje, permanece como um filme pouco comentado da carreira de Lars von Trier.

Entretanto, muitos dos elementos que se tornariam marcantes na obra do cineasta parecem estar prefigurados neste trabalho, sobretudo no que diz respeito às estratégias de convocação da "participação afetiva"4 do espectador,

3. Em 1981, Lars von Trier foi o primeiro aluno da Escola de Cinema da Dinamarca a ser premiado no Festival Europeu de Escolas de Cinema de Munich, com o curta-metragem Nocturne. Em 1982, seu média-metragem Images of relief (Befrielsesbilleder), produzido como trabalho de conclusão de curso, venceu o prêmio especial do mesmo festival, tendo sido exibido comercialmente em salas de cinema da Dinamarca e transmitido na Grã-Bretanha pela rede Channel4 Television, patrocinadora do evento.

4. Edgar Morin (1970, p. 117) nota que a impressão de realidade produzida pelas imagens cinematográficas conduz a um impulso de participação. Como no cinema, no entanto, encontramo-nos fora da ação e privados da participação prática, tem-se uma participação afetiva ou subjetiva. Morin considera a participação afetiva como um equivalente do complexo de "projeções-identificações" que levaria o espectador de cinema simultaneamente a projetar sua subjetividade no filme e assimilar em si, identificando-se, aquilo que é projetado no écran. A perspectiva é semelhante à assumida por Christian Metz, no artigo A respeito da impressão de realidade, no qual afirma que a impressão de realidade desencadeia no espectador um processo ao mesmo tempo perceptivo e afetivo de participação (METZ, 1977, p.16, grifo meu). No presente trabalho, a participação afetiva é compreendida como a capacidade do espectador de reagir afetivamente ao filme, em especial às personagens e situações narradas. Optouse por evitar o termo "identificação", para tentar minimizar ambiguidades, dadas as controvérsias que envolvem hoje o termo e à variedade de sentidos a ele atribuídos. Alguns autores, como Odin (2000, p. 40) compreendem a identificação como um dos mecanismos envolvidos no processo de participação afetiva. Já Jullier e Marie (2009, p. 68-69) defendem o termo "participação" como uma alternativa a "identificação", aderindo às críticas cognitivistas ao uso do conceito pela tradição dos estudos semiopsicanalíticos. 
ou dos "modos de produção de afetos" 56 . O objetivo deste artigo é desvendar a natureza destas estratégias, demonstrado como, já durante esta fase inicial da carreira do cineasta, é possível observar em sua obra a emergência de uma série de problemas relacionados à expressão e à convocação da experiência afetiva do espectador pelo cinema narrativo de ficção. Tais problemas - que tensionam os limites entre categorias como aproximação e distanciamento, além de provocar reflexão sobre os limites éticos do manejo dos afetos do espectador - parecem estar ligados diretamente ao interesse por um tipo específico de experiência afetiva, caracterizada por reações excessivas e instintivas, que envolvem o espectador num nível corporal.

\section{diálogo com as estratégias dos gêneros de corpo}

No artigo Film bodies: gender, genre and excess, Linda Williams (1991) direciona sua atenção para certos gêneros de filmes, classificados comumente como de "mau gosto" e desvalorizados pelo apelo sensacionalista e mesmo grosseiro a respostas que são de uma natureza não reflexiva nem muito menos estética, mas quase inteiramente instintiva. Williams classifica como "gêneros de corpo" ao horror, à pornografia e ao melodrama - mais especificamente aos chamados filmes para mulher ou wheepies (filmes para chorar). Tais gêneros

5. Em seu modelo semiopragmático, Roger Odin fala, na verdade, em "modos de produção de sentidos e afetos", ressaltando, em apoio à tese do pesquisador cognitivista Torben Grodal, que "processos cognitivos e processos emocionais são indissociáveis ou no mínimo intimamente ligados" (ODIN,2000, p. 38). O presente artigo segue esta mesma perspectiva. É só, portanto, por um esforço de abstração que se fala aqui na convocação da dimensão afetiva da experiência do espectador. Uma análise como a proposta neste artigo não tem como ser realizada sem um exame também da dimensão dos sentidos; do trabalho cognitivo de construção da narrativa.

6. A questão da experiência afetiva do espectador é hoje alvo do interesse de diversas correntes teóricas, que raramente dialogam entre si. No presente artigo, optou-se por um enfoque que articula a abordagem semiopragmática proposta por Odin (2000) a contribuições cognitivistas. Vale ressaltar, no entanto, que o termo "afetos" vem sendo largamente empregado também dentro da tradição pós-estruturalista, tendo como referência central reflexões desenvolvidas por Deleuze $(1983,2005)$ a partir de Spinoza e Bergson. Neste contexto, fala-se em uma "virada afetiva" (affective turn) em contraposição à "virada linguística", que marcou o domínio da semiótica e da semiologia nos anos 60 e 70, ou à "virada cultural" dos anos 80 e 90, auge da disseminação dos estudos culturais (CLOUGH; HALLEY, 2007, p. 9) 
ano 2 número 4

Temáticas

Livres

teriam em comum o fato de visar de modo muito direto uma certa "afetação" do corpo do espectador ao explorar o "espetáculo de um corpo capturado sob o domínio de intensa emoção e sensação" (WILLIAMS, 1991, p. 4). Não raras vezes, lembra ela, o sucesso destas produções é medido pela intensidade das respostas fisiológicas que produzem, seja excitação sexual, batimentos cardíacos acelerados pelo medo ou lágrimas de profunda tristeza.

A autora vê em operação nestes filmes um "sistema de excesso", e procura refletir sobre a função e o sentido deste excesso, do modo aparentemente gratuito como estes gêneros exploram a violência, a sexualidade ou a dor emocional. Uma das suas principais preocupações é com as questões de gênero (no sentido de feminino e masculino) implicadas nos modos como estes filmes se endereçam ao espectador, e nas fantasias que eles encenam.

Para o efeito do nosso trabalho, a categoria dos "filmes de corpo" criada por Williams é interessante para ajudar a compreender algumas estratégias evidentes em Epidemic e em outros filmes de Lars von Trier. Não por acaso, a obra do cineasta dinamarquês dialoga, com frequência, com as estratégias das produções de "baixa cultura" a que Williams se refere. O melodrama - e o universo dos tears jerkers - é o exemplo mais óbvio, referência central para os filmes da Trilogia do Coração de Ouro, em especial Ondas do destino (Breaking the waves, 1996) e Dançando no escuro (Dancer in the dark, 2000) como atestam inúmeras análises (BAINBRIDGE, 2007; FURUITTI, 2003; OLIVEIRA, 2008; RODRIGUES, 2006; SIMONS, 2007). Seu próximo filme, The nymphomaniac, está sendo anunciado como um projeto pornô, com uma versão hardcore para exibição em festivais e outra mais leve, formatada para o circuito comercial.

Em Epidemic - e também em Antichristo (2009) e na minissérie para a televisão $O$ Reino (Riget, 1994) - são as convenções do horror que marcam presença. No filme aqui analisado, Lars von Trier e o roteirista Niels Vorsel interpretam a si mesmos. Às vésperas de entregar ao produtor os originais de um roteiro, eles descobrem que o disquete com o arquivo do texto foi 
danificado. Decidem então escrever um roteiro inteiramente novo. Quando Niels datilografa numa folha de papel em branco o título Epidemic, aos sete minutos do filme, dando início à elaboração do roteiro, um narrador em voice over anuncia para o espectador uma "coincidência sinistra e fantástica": durante os cinco dias em que aquele roteiro foi criado e escrito, uma epidemia real se aproximava. Sua erupção coincidiu com a finalização do trabalho. A sequência mostra um apartamento abandonado, com cacos de louça e uma garrafa espalhados no chão, sangue escorrendo na parede e uma poça sobre a mesa. Tudo mostrado em lentos e solenes travellings, com efeitos de fusão entre as imagens e o acompanhamento ainda mais solene de um trecho da abertura da ópera Tannhäuser, de Wagner.

A partir daí, a narrativa (que se divide em cinco capítulos, um para cada dia de trabalho) irá se bifurcar em duas linhas de ação, acompanhando por um lado Lars e Niels no processo de construção do roteiro; e por outro, as cenas do filme que eles criam: a história de Dr. Mesmer, um médico idealista da Idade Média - interpretado pelo próprio von Trier - que parte numa jornada para salvar as vítimas da peste, sem saber que ele próprio espalha a doença.

A referência ao horror é evidente em certas escolhas estilísticas. Na composição de algumas imagens, há distorções e jogo de luz e sombra que remetem à estética dos filmes do expressionismo alemão dos anos 20, como O gabinete do Dr. Caligari (1922) e Nosferatu (1920). Em outros momentos, Epidemic parece mais próximo das produções de terror "B" mais recentes, seja pela evidente precariedade dos recursos empregados nos "efeitos especiais", pelos efeitos sonoros à base de sintetizadores que pontuam a narrativa, ou ainda pela exploração de imagens repulsivas, sobretudo na sequência final, com a mostração em plano detalhe de feridas e furúnculos provocados pela epidemia. 
ano 2 número 4

Temáticas

Livres
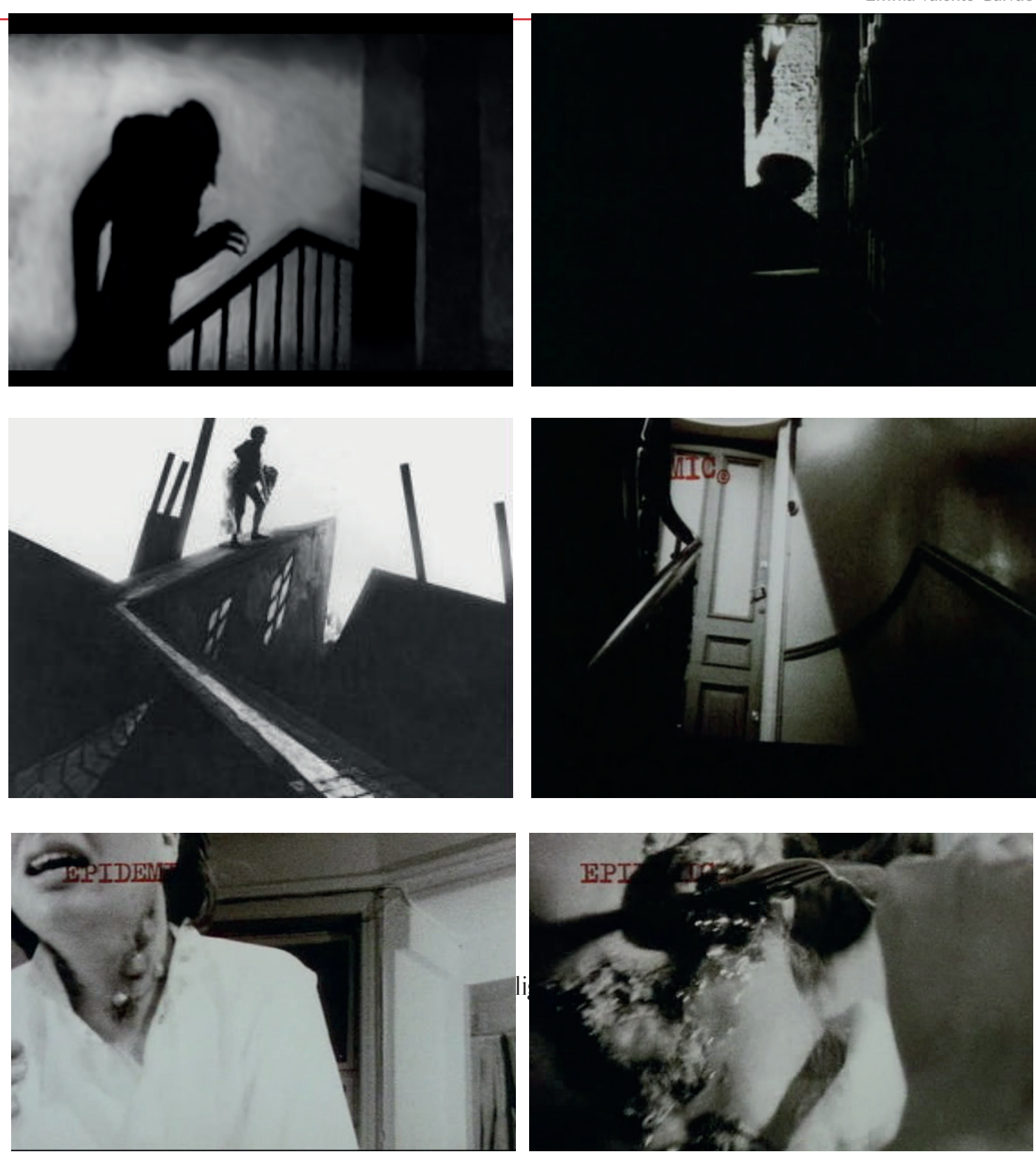

Imagens repulsivas na sequência final de Epidemic remetem aos filmes "B" de terror

Se as obras do expressionismo alemão dos anos 20 gozam de prestígio dentro de uma tradição de culto ao cinema como arte, o mesmo não pode ser dito das produções de horror de baixo orçamento com as quais von Trier também flerta em Epidemic - e que se enquadrariam mais facilmente na categoria "filmes de corpo" proposta por Williams. A desvalorização dessas obras não parece derivar apenas de questões formais ou estéticas. 
que os gêneros fílmicos que obtiveram um status cultural especialmente baixo, que parecem existir como excesso mesmo para o sistema dos gêneros populares, não são simplesmente aqueles que apresentam de modo sensacionalista corpos na tela e registram efeitos no corpo dos espectadores. Antes, o que marca especialmente estes gêneros do corpo como "baixos" é a percepção de que o corpo do espectador é capturado em um mimetismo quase involuntário da emoção ou da sensação do corpo na tela, ao lado do fato de que o corpo apresentado é feminino.․'(WILLIAMS, 1991, p.4)

A referência ao corpo feminino aí é controversa e seu exame exigiria toda uma discussão sobre gênero que escapa ao escopo desse trabalho. De qualquer forma, o que parece evidente nesta discussão é a emergência de um problema ético. Quais os limites válidos no cinema para a manipulação de afetos, sobretudo quando se visam de modo muito direto reações corporais instintivas, que fogem ao controle do espectador? E mais: até que ponto o desconforto em relação a estas experiências emocionais e sensoriais orientam julgamentos sobre as obras? A qualidade de um filme pode ser medida por este tipo critério?

Ao incursionar pelo território dos "gêneros de corpo" (e, sobretudo, no contexto de um cinema autoral, de investigações formais), a obra de von Trier problematiza questões como estas. Para entender, no entanto, como um tipo de efeito é produzido é preciso desvendar, em primeiro lugar, a natureza das estratégias empregadas pelo diretor para perseguir um tipo de imersão, quase mimética, na diegese. Na sequência final de Epidemic, que mostra uma sessão de hipnose de consequências catastróficas, estas estratégias podem ser identificadas claramente. Por esta razão, tal sequência será alvo a seguir de um exame mais detalhado.

7. There are, of course, other film genres which both portray and affect the sensational body-e.g., thrillers, musicals, comedies. I suggest, however, that the film genres that have had especially low cultural status- which have seemed to exist as excesses to the system of even the popular genres- are not simply those which sensationally display bodies on the screen and register effects in the bodies of spectators. Rather, what may especially mark these body genres as low is the perception that the body of the spectator is caught up in an almost involuntary mimicry of the emotion or sensation of the body on the screen along with the fact that the body displayed is female. 


\section{Empatia, mimetismo e imersão na diegese}

ano 2 número 4

Temáticas

Livres

A cena dura 24 minutos, integrando a quinta e última parte da narrativa. Lars, Niels e a mulher de Niels, Suzzane, recebem o assessor do Instituto de Cinema da Dinamarca Claes Kastholm ${ }^{8}$ para um jantar onde o roteiro será apresentado. Lars conta a história do filme dentro do filme, revelando o seu final: contaminado pela doença e com todos ao ser redor mortos, Dr. Mesmer ajoelha e agradece a Deus pela vida que teve. Ao ouvir o relato, o produtor se mostra insatisfeito, não só com o teor da narrativa ("Eu estava esperando mais ação") como com as dimensões do roteiro ("Apenas 12 páginas após um ano e meio de trabalho?"). Lars, então, conta que preparou uma surpresa, para apresentar o filme "de um modo menos tradicional". Alguns instantes depois chegam ao apartamento um hipnotizador e uma mulher. Ele vai sugestioná-la, transportando-a psiquicamente para dentro das paginas finais do roteiro. $\mathrm{O}$ que se segue pode ser descrito como a exibição do "espetáculo de um corpo capturado sob o domínio de intensa emoção e sensação", para citar Williams (1991, p. 4) mais uma vez. O transe hipnótico leva a mulher progressivamente a se descontrolar, ingressando num estado de total horror e desespero, que culmina com o aparecimento de chagas no seu corpo e no corpo das outras pessoas que estão na sala. A epidemia fictícia contaminou a "vida real".

É interessante notar que, ao contrário do que acontece em outros momentos da narrativa, aqui não são inseridas imagens do filme dentro do filme. É apenas por meio da fala e das afetações no corpo da hipnotizada que o espectador pode ter acesso às cenas do roteiro. Toda a encenação evolui a partir de um contraponto entre os planos que mostram a mulher e aqueles que revelam os olhares dos que estão em torno dela (reaction shots), além de algumas rápidas tomadas que prometem ao espectador a revelação de informações privilegiadas,

8. O sistema de subvenção às produções do cinema dinamarquês é realizado por meio de uma equipe de assessores vinculados ao Instituto de Cinema da Dinamarca que selecionam os filmes a serem financiados e acompanham o seu processo produtivo. Um dos assessores do Instituto na época, Claes interpreta a si próprio em Epidemic. Consta inclusive que o filme foi resultado de uma aposta entre Claes e Lars von Trier, que garantiu ao consultor que seria capaz de realizar um filme comercial com apenas um milhão de coroas, quantia considerada baixíssima para a produção de um longa-metragem no país à época. (STEVENSON, 2005, p. 69). 
manobrando expectativas em relação à iminente disseminação da epidemia: o plano detalhe de uma ferida na mão de Niels, o zoom na janela do apartamento em frente, uma movimentação de carros na rua. Nos dois últimos exemplos, inclusive, insinuam-se acontecimentos que nunca serão explicados nem terão qualquer desdobramento para a narrativa.

De qualquer forma, o foco central da cena é muito claramente o transe hipnótico. A princípio, a personagem, tensa, com os olhos fechados, descreve as imagens: "Eles têm medo da infecção e da morte; estão sofrendo profundamente". Em seu redor, Lars, Niels, Suzanne e o produtor Claes a olham com curiosidade e risos de ironia. Aos poucos, porém, suas expressões assumem um ar tenso, de desconforto. A mulher vai ficando cada vez mais transtornada: primeiro trêmula, gemendo e chorando, com as mãos sob o rosto e o pescoço; depois em pé, soltando gritos e urros e sacudindo todo o corpo. Ela se lança contra a parede e em seguida salta sob a mesa, enfiando violentamente um garfo na enorme ferida que surge em seu pescoço.

Na escala de planos, de modo geral, os planos mais longos e aproximados são reservados à mostração do transe. Enquanto as reaction shots de Lars, Niels, Claes, e Suzzane duram em média dois a seis segundos, as tomadas focalizando o corpo e principalmente o rosto da mulher hipnotizada chegam a se prolongar por quase um minuto. O tempo se dilata para a exibição minuciosa da evolução das respostas emocionais e sensoriais extremas. Após o momento de maior intensidade da cena (o extremo close up da ferida) o ritmo se acelera bruscamente. Resultado: enquanto a evolução do transe se prolonga por 10 minutos, menos de dois são necessários para narrar, de forma elíptica, a disseminação final da epidemia entre os demais presentes na sala?.

O que mais chama atenção nesta cena é o modo como ela parece apelar para o que os psicólogos chamam de mimetismo afetivo (affective mimicry).

9. Os instantes finais remetem diretamente à sequência inicial, com a música solene de Bach, suaves travellings e fusões entre as imagens, sugerindo a passagem do tempo: Suzanne caída ao lado da parede cheia de sangue. Claus em estado de choque, von Trier na mesa diante do corpo em espasmos da jovem e Niels no chão da varanda com o corpo cheio de feridas. 
ano 2 número 4

Temáticas

Livres
A ideia de um mimetismo afetivo advém da observação do fenômeno dos reflexos-espelho (mirror reflexes) ou mimetismo motor (motor mimicry), uma tendência dos indivíduos de imitar aspectos dos gestos e expressões faciais de seus interlocutores ou de pessoas que observa - como quando esboçamos uma expressão de dor ao ver o sofrimento de alguém. Trata-se de uma resposta automática e involuntária que teria a função de permitir ao sujeito obter informações sobre o estado mental daqueles com quem se relaciona. Além disso, presume-se que a repetição das expressões aciona uma resposta afetiva: a pessoa capta algo do sentimento do outro. Daí a ideia de um mimetismo afetivo ou contágio emocional.

Alguns pesquisadores cognitivistas do cinema veem no modo como certos filmes se apropriam de recursos como o close up um apelo à comoção emocional via efeitos de mimetismo. Plantinga (1999, p. 239) identifica numa série de produções norte-americanas a recorrência do um tipo de cena de apelo ao mimetismo afetivo, a que ele chama de "cena da empatia". Nestas cenas - que com frequência aparecem nos finais dos filmes - o ritmo da narrativa se reduz e a atenção se volta para experiência interior de um personagem. Usa-se muito o close-up, em planos ou estrutura de planos longos, com a utilização da música, empaticamente, como reforço.

Treze anos depois de Epidemic, von Trier adotaria uma estratégia do gênero na sequência final de Dançando no escuro, que se demora na mostração de todo o horror e desespero da protagonista instantes antes de ser enforcada. Curiosamente, aqui também a mise en scène é construída a partir de um contraponto entre as expressões de uma personagem e os olhares daqueles que a observam ${ }^{10}$.

10. É digno de nota também o fato de que tanto em Dançando no escuro quanto em Epidemic, os urros das personagens pontuam mais a intensidade dramática da cena do que o recurso da música extradiegética. Na sequência do enforcamento de Selma, o canto à capela da personagem marca o fim de seu tormento e a redenção final, instantes antes da morte. Em Epidemic, há um som muito breve de sintetizadores apenas no momento em que a personagem crava o garfo na ferida, já no final do transe. 

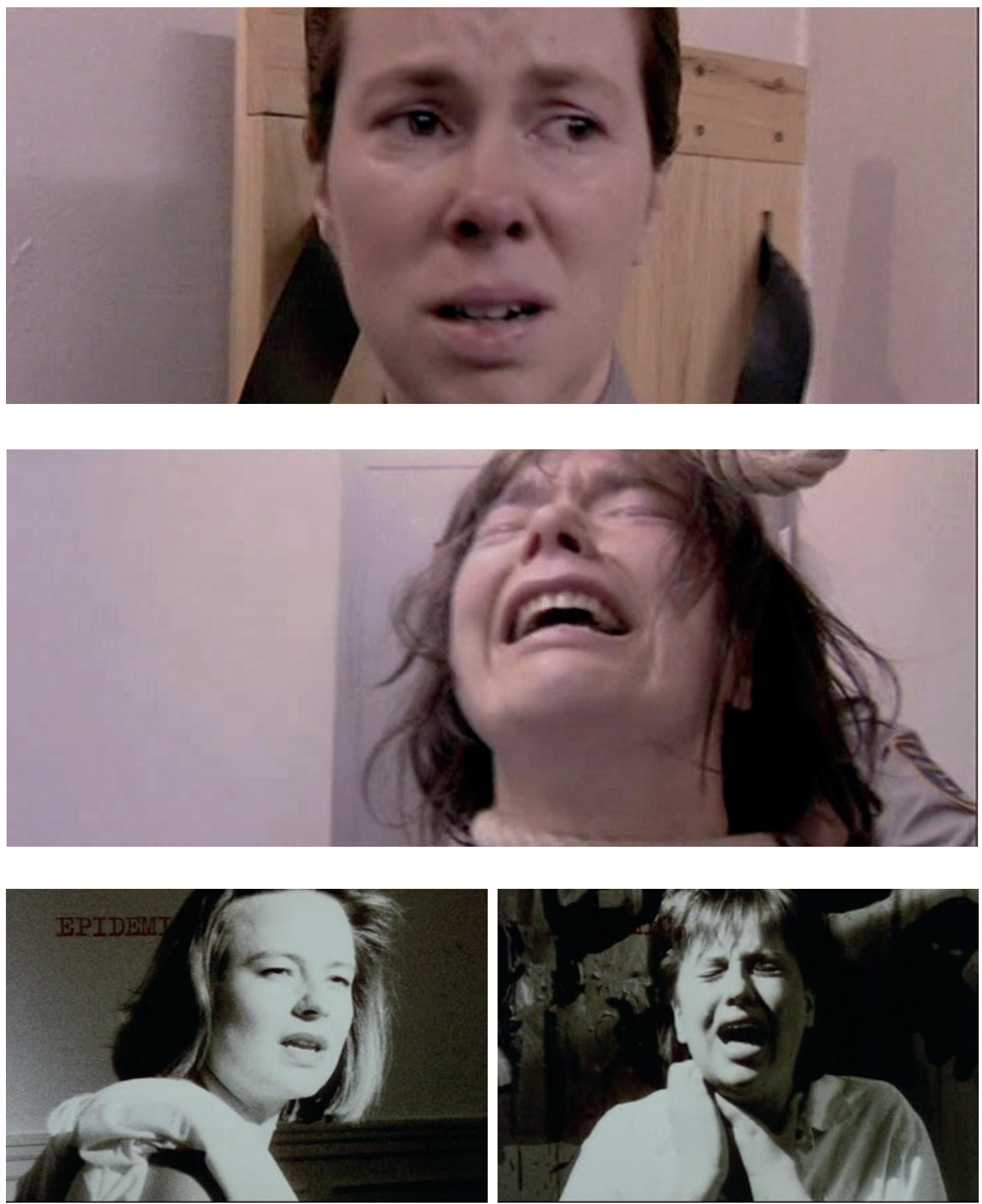

No alto, a cena do enforcamento em Dançando no escuro. Abaixo, a sessão de hipnose em Epidemic.

No caso de Epidemic, um dado interessante é que ao mesmo tempo em que a "cena da empatia" convoca de forma muito intensa e excessiva a participação afetiva, ela pode ser compreendida também como um comentário sobre o poder do cinema de levar o espectador a uma profunda imersão na diegese. Afinal, não são as cenas de um filme imaginário que afetam de modo tão visceral a personagem, a ponto de fazer com que a epidemia fictícia contamine a "vida 
ano 2 número 4

Temáticas

Livres

real"? Como se sabe, a analogia entre o transe hipnótico e a experiência do espectador é recorrente nos estudos sobre cinema (BERTON, 2009; MORIN, 1971; BARTHES, 1975). Nos filmes que formam a Trilogia Europa de Lars von Trier (que inclui, além de Epidemic, O Elemento do crime e Europa), o cineasta faz várias referências ao tema ${ }^{11}$. Anos mais tarde, ele chegou a comentar, numa entrevista a respeito de Ondas do destino (Breaking the waves) - que aqueles seus três primeiros filmes "eram sobre hipnose" enquanto a produção mais recente "era hipnose", dado ao apelo realista do estilo semidocumental"12 (VON TRIER apud LUNHOLDT, 2003). Tão importante, portanto, quanto a afetação do espectador é o modo como esta afetação é problematizada em Epidemic, por meio de uma série de jogos metalinguísticos inseridos na narrativa.

\section{Reflexividade, impressão de realidade e afeto}

Ao construir a narrativa de Epidemic como um pseudodocumentário sobre o processo de elaboração de um roteiro, Lars von Trier cria condições para colocar em cena uma série de reflexões sobre o seu ofício como roteirista e diretor, e mesmo sobre as condições de produção na indústria cinematográfica da Dinamarca. Aos 24 minutos do filme (na segunda parte, intitulada A linha), Lars e Niels aparecem pintando na parede do apartamento a linha dramática da narrativa que estão construindo. "Um filme deve ser como uma pedra no sapato", diz o "personagem" von Trier, numa sentença que se configura claramente também como um comentário do von Trier cineasta, para além da diegese.

Já na cena do jantar, o produtor Claes fala da junta direcional que controla a indústria cinematográfica naquele "pequeno país" (e que exige roteiros com no mínimo 150 páginas), além de comentar, lamentando, que nos

11. O elemento do crime (1984) começa com um psicoterapeuta hipnotizando um detetive para que ele recorde os acontecimentos do passado. Em Europa (1991), um soturno narrador em voice over (interpretado por Max von Sidow) dá os comandos de contagem regressiva que irá transportar o espectador para a narrativa ("Quando eu contar até 10, você estará em...Europa").

12. We try to make it look like reality with the semi-documentary style, which means that it is hypsosis while the others film are about hypnosis (tradução livre). 
"filmes dinamarqueses há menos gritos e sangue do que alguns querem". A compreensão do contexto da produção de Epidemic e das estratégias adotadas pelo cineasta num nível extratextual ajudam a lançar uma luz diferente sobre estes trechos de diálogo, aparentemente sem muita importância para a narrativa. Isso porque à época do lançamento do filme, Lars von Trier (àquela altura um cineasta ainda jovem e em fase de afirmação), costumava fazer críticas contundentes tanto aos instrumentos de fomento ao cinema no seu país quanto às produções de seus pares. Nesse contexto, ele contrapunha-se, com frequência, às produções comprometidas com questões políticas e sociais e a toda uma tradição humanista de recusa ao cinema de apelo sensacionalista (LUMHOLDT, 2003, p. 6).

Para além das brincadeiras metalinguísticas ${ }^{13}$, no entanto, o que parece caracterizar de modo mais exato o exercício de reflexividade aqui empreendido é a opção por uma estética do descuido ou do "mal feito", como se malogros na construção da narrativa audiovisual - de inverossimilhanças no roteiro à precariedade dos recursos empregados nos cenários e ambientações - pudessem ser utilizados para intensificar no espectador a consciência do filme enquanto artefato, tornando visíveis para ele as tais marcas da enunciação fílmica.

Em Epidemic, esta estratégia é usada de modo exaustivo. As cenas do "filme dentro do filme" parecem esboços de cenas, tão improvisadas e inconsistentes como o roteiro que Lars e Niels tentam elaborar às pressas, para cumprir o prazo de cinco dias. Numa delas, Dr. Mesmer (também interpretado por von Trier) inicia sua jornada de mártir pairando no ar sob os campos de trigo ao som

13. Outro jogo interessante efetuado em Epidemic diz respeito às instâncias narrativas. Ao longo do filme, duas diferentes vozes são ouvidas na narração em voice over, que antecipa informações não disponíveis para os personagens. Mais curioso, no entanto, é um diálogo em off ouvido no início do filme. Lars está no apartamento com Niels, falando ao telefone com o produtor Claes. Depois que ele desliga, uma rápida cena mostra um homem de casaco em um telefone público. A imagem é acompanhada pelo seguinte diálogo em off: “ - O que Claes está fazendo ali? - Comprou uma capa de chuva.- Outra? - Ele tem fetiche com isso". Retrospectivamente, o espectador atento de Epidemic poderá reconhecer ao assistir pela segunda vez o filme a figura de Claes (apresentada oficialmente só na cena final do filme) como o homem de casaco de chuva, e as vozes misteriosas como sendo de Lars e Niels. A situação sugere que a dupla transitou da ação narrada para um lugar externo à diegese, de personagens a espectadores ou mesmo narradores do filme. 
ano 2 número 4

Temáticas

Livres

de Richard Wagner - e pendurado por um cabo a um helicóptero, a despeito de sua história se passar na Idade Média. Mesmo a narrativa da "vida real" parece construída de modo displicente - pelo menos sob os critérios clássicos. Não raras vezes o roteiro se demora longamente em situações gratuitas e mesmo bizarras, que não "empurram a ação para frente" nem parecem ter uma correlação significativa com o resto da trama. É o caso do episódio em que Niels narra para Lars sua troca de correspondência com adolescentes de Atlantic City ${ }^{14}$ ou a cena em que os dois abrem um tubo de Signal Plus, por conta da semelhança entre a pasta de dentes listrada e a descrição do "pus bicolor" que encontraram nos relatos medievais sobre a peste.

Inteiramente rodado em preto e branco, Epidemic se vale de recursos técnicos e formais para deixar clara ao espectador a distinção entre as cenas da "vida real" e aquelas do filme dentro do filme. Nas primeiras, o som é direto e as imagens foram captadas no formato $16 \mathrm{~mm}$, característico do documentário, enquanto nas segundas, usa-se filme $35 \mathrm{~mm}$, com som pós-sincronizado seguindo o padrão mais tradicional dos filmes ficcionais da grande indústria. Longos e fluidos travellings, além do uso de composições com profundidade de campo em algumas cenas, contribuem também para conferir uma estética própria à narrativa da trajetória de Dr. Mesmer - distinta da reservada às cenas que mostram Lars e Niels como roteiristas, com reenquadramentos e zoons abruptos que podem ser associados a um registro documental e mesmo espontâneo ou amador.

Não é difícil reconhecer em Epidemic, em embrião, estratégias que remetem à proposta do movimento Dogma 95 - lançado por Trier e Vinterberg oito anos depois. Ainda que não se tenha aqui o estilo de montagem com saltos bruscos (jump cuts) que notabilizou o Dogma (e marcou presença em boa parte dos trabalhos do cineasta, a partir dos anos 90) é evidente já neste filme o movimento na direção de produzir um apelo realista a partir da criação de uma atmosfera falsa de documentário - um recurso que se tornaria bastante comum

14. Nesta sequência, Niels afirma ter o projeto de escrever sobre a América de modo similar a Kafka, sem nunca viajar até lá. Anos mais tarde, Trier diria a mesma coisa a respeito de Dogville, anunciado como a primeira parte da trilogia EUA - Terra das Oportunidades. 
nas últimas décadas em produções vinculadas a uma certa tendência realista do cinema contemporâneo (SALOMÃO, 2005).

Odin (2000, p. 70) acredita que as figuras do "mal feito" (planos movimentados, oscilantes, com imagens "mal enquadradas") podem assumir um papel, nos dias de hoje, de um tipo de senha para um modo de leitura documentarizante. No entanto, ressalta ele, estas figuras nem sempre têm o "efeito documentarizante" como costumam ter as senhas exteriores ao texto, dadas previamente ao espectador - como as informações veiculadas em posters, traillers e outros materiais de divulgação. “Em certas produções do cinema experimental", continua Odin (2000, p. 70), "elas funcionam como uma máquina de guerra contra o cinema dominante e como figuras de valor estético"15. O manifesto Dogma - com suas críticas às grandes produções e ao padrão hollywodiano - parece indicar que esta é uma leitura adequada para o emprego que Trier realiza das "figuras do mal feito".

Do ponto de vista da produção dos afetos, no entanto, qual o impacto visado por esta estratégia? Na sequência final de Epidemic, já analisada, a simulação do registro documental pode ser entendida como um apelo extra à imersão do espectador, conferindo uma espécie de valor adicional de verdade à narrativa. Estratégias extratextuais inclusive parecem ter sido utilizadas também com este sentido: em entrevistas, o diretor afirmou na época que a jovem que aparece em cena teria sido realmente hipnotizada durante as filmagens (LUMHOLDT, 2003).

Ao mesmo tempo, a estratégia também se incorpora aos exercícios de reflexividade propostos em Epidemic. Isso porque, ao contrário do realismo clássico, que visaria à transparência, a estética realista perseguida por Trier se apropria, como já foi dito aqui, das "figuras do mal feito" para chamar atenção para a materialidade do filme, para a ficção enquanto farsa, manipulação,

15. Cependent, ces figures ne produisent pas toujours un effect documentaire: dans certaines productions du cinéma experimental, par example, elles fonctionnent comme une machine de guerre contre le cinema dominant et comme des figure à valeur esthétique 
ano 2 número 4

Temáticas

Livres artifício $^{16}$. Nesse sentido, ela contribuiria para afastar o espectador da diegese, promovendo distanciamento em relação às emoções e sensações do personagem e reduzindo, portanto, a participação afetiva do espectador.

Como entender este paradoxo? Com frequência, nos estudos sobre o cinema, a participação afetiva foi compreendida como uma consequência do efeito de impressão de realidade produzido pelas imagens em movimento (MORIN, 1971). Logrado (mesmo que por uma voluntária suspensão da descrença) pela semelhança entre as imagens na tela e sua experiência subjetiva de percepção da realidade, o espectador tenderia a reagir afetivamente às situações encenadas de um modo muito direto, mimetizando as emoções dos personagens.

Mas até que ponto a participação afetiva depende mesmo da impressão de realidade? Odin (2000, p. 20) elabora uma reflexão sobre as distinções entre diegetização e impressão de realidade que pode ajudar a lançar luz sobre esta questão. O autor lembra que a impressão de realidade é um fenômeno ligado a certos traços da matéria de expressão da linguagem cinematográfica, como o movimento das imagens e o som sincronizado. Outras linguagens, como o texto escrito, por exemplo, seriam incapazes de produzir impressão de realidade. Não obstante, seria um erro deduzir que elas são incapazes de produzir um efeito diegético. A prova disso é que a leitura de um romance é capaz de propiciar um "efeito de mundo" tão ou mais intenso que a apreciação de um filme.

A capacidade de uma linguagem de produzir um efeito diegético não tem nada a ver com sua capacidade de produzir impressão de realidade. Podese mesmo concluir que a impressão de realidade seja o principal obstáculo à diegetização. Para um espectador de hoje, face às produções do cinema dos primeiros tempos, é a impressão de realidade que, denunciando os cenários como tecidos pintados, bloqueia a diegetização em proveito da construção de um espaço espetacular (de um espaço que se denuncia como uma construção efetuada em vista de um espetáculo versus um mundo

16. O exemplo talvez mais claro deste tipo de estratégia está em Os idiotas. Única produção de Lars von Trier a receber o selo Dogma, o filme traz várias cenas onde é possível visualizar o aparato técnico das gravações, com microfones e a câmera refletida no espelho. 
no qual eu posso crer). O mesmo na televisão, é a impressão de realidade que, fazendo-me ver uma cena de teatro com cortinas, cenários e atores (...) ou um estúdio com microfones, câmeras e praticáveis (como se produz todos os dias), me convida a espetacularizar (a tomar consciência de que eu estou diante de um espetáculo) e não a diegetizar (a entrar em um mundo) ${ }^{17}$. (ODIN. 2000,p. 20).

Quando, portanto, na cena final de Epidemic, Trier persegue reações de mimetismo afetivo ao apelar para a mostração de um corpo com reações emocionais e sensoriais intensas, é o fenômeno de impressão de realidade que parece estar sendo usado a favor da imersão na diegese e, consequentemente, da participação afetiva do espectador. Em contrapartida, ao expor em cena o helicóptero que permite a Dr. Mesmer deslizar no ar é à consciência do cinema enquanto espetáculo - reflexiva e distanciada do pathos do personagem - que o filme parece se endereçar.

Em trabalhos posteriores, os dois tipos de estratégias se apresentam de forma ainda mais imbricada, como se o objetivo fosse conduzir o espectador a transitar continuamente entre modos de apreciação radicalmente diversos - ou talvez testar os limites para manter o espectador imerso na narrativa, mesmo diante de uma exposição ostensiva dos artifícios da encenação. Os filmes da inconclusa Trilogia EUA - Terra das Oportunidades, Dogville (2003) e Manderlay (2005) são exemplares nesse sentido, com o exercício de um distanciamento brechtiano (na opção pelo não-cenário e na narrativa em forma de parábola) associados a recursos tradicionalmente usados para convocação da empatia, como os close-ups valorizando as expressões e olhares dos personagens.

Muitas vezes, na obra de von Trier, esta contraposição é lida como uma contraposição entre artifício e autenticidade (BAINBRIDGE, 2007), entre uma

17. Il peut meme arriver que l'impression de réalité soit le principal obstacle à la diégétisation. Pour um spectateur d'aujourd' hui,parexample, face aux productions du cinema dês premiers temps, c'est l'impression de réallité qui, em dénonçant les décors comme dês toiles peintes, bloque le diégétisation ao profit de la construction d'un space spectaculaire (d'un espace que se dénonce comme une construction effetué em vue d'un spectacle vs um monde dans lequel on peut croire). De même à la télévision, c'est laimpression de réalité qui, en me faisant voir uns scène de théatre avec rideaux, décors e acteurs (...) ou um plateau de télévision avec micros,câmeras et praticables (comme cela se produit tous le jours), m'invite à spectaculariser (à prendre conscience que jê suis face à um spectacle) et non à diégétizer (a entrer dans le monde). 
ano 2 número 4

Temáticas

Livres mise en scène de apelo realista, que persegue a "verdade" no corpo dos atores/ personagens e uma representação altamente estilizada ${ }^{18}$, que se revela como jogo de pura convenção. Nos demais filmes da Trilogia Europa, $O$ elemento do crime e Europa, a opção recaia de maneira mais simples sobre a estilização: são filmes com planos cuidadosamente planejados, que chamam atenção pelo uso de recursos como back projections e efeitos expressionistas na fotografia.

É em Epidemic, portanto, que a opção pela contraposição começa a se delinear a partir, inclusive, dos dois registros em que a narrativa se bifurca e que já foram citados aqui: o "da vida real”, que apela para uma leitura documentarizante, e o do filme dentro do filme, estilizado a ponto de se revelar como uma absurda farsa $^{19}$. Esta faceta farsesca do filme (que contamina também o registro documentarizante) será melhor examinada a seguir, quando retomarmos o problema das relações entre a retórica moral e apelo afetivo.

\section{Farsa e alegoria, retórica moral e afeto}

Filmes se valem de crenças e valores morais disseminados na sociedade para manejar os afetos do espectador. Ao mesmo tempo, se utilizam do trabalho de produção de afetos para transmitir valores e crenças. Estas relações são

18. Esta estilização pode levar ao que Odin (2000, p. 42) chama de "defasagem", quando os parâmetros fílmicos (o trabalho plástico, rítmico e musical do filme) ganham autonomia em relação à narrativa, chamando atenção para si mesmos em lugar de contribuir para que o espectador vibre ao ritmo dos eventos narrados. Como um exemplo de defasagem estética, Odin cita sua própria reação a um filme como Betty Blue (37.2 le matin, 1986), de Jean Jacques Beineix, com seus "belos cenários", "De modo geral, as imagens muito belas e a estética publicitária de muitos filmes recentes me incomodam e bloqueiam minha participação nas aventuras que se querem, todavia, altamente geradoras de emoção". No original: "D’une façon génerale,les trops belle images et l'esthetique plubicitaire de bien dês films récents me gênent e bloquent ma participation à dês aventures qui se veulent pourtant hautement géneratrices d'emotion. O autor (2000, p.43) ressalta, ainda, que certos filmes perseguem voluntariamente um efeito de defasagem, seja de modo generalizado (como nos filmes experimentais, onde a estruturação do filme como narrativa depende de uma competência do espectador) ou por meio de uma autonomização produzida a partir de um sistema de oposições inscrito no próprio filme.

19. Em Dançando no escuro (2009) uma estratégia semelhante é adotada graças aos elementos formais que pontuam uma rígida distinção entre as cenas da "vida real" da protagonista e aquelas que descrevem os seus delírios musicais. Também em Antichristo (2009), o cineasta parece oscilar entre imagens altamente estilizadas (como a sequencia inicial, que dialoga esteticamente com Tarkówski) e um estilo mais despojado, focado no trabalho do ator, como nos filmes do Dogma. 
bem conhecidas e notadas por diversas vertentes teóricas, incluindo autores cognitivistas e aqueles que se mantém mais fieis à tradição francófona dos estudos inspirados na semiologia e na psicanálise.

No segundo grupo, Odin (2000, p. 45) ressalta as relações entre o que ele chama de mise en phase e o processo de transmissão de valores. Compreendida como uma modalidade da participação afetiva do espectador, a mise em phase é definida pelo autor como "os processos que me conduzem a vibrar ao ritmo daquilo que o filme me dá a ver e compreender" ${ }^{20}$. Para Odin, a mise en pháse narrativa é um operador formidável para levar o espectador a aderir aos valores expressos pela narrativa, chegando a atuar mesmo como um produtor de valores. No filme de ficção clássico, prossegue Odin, o processo funciona, com frequência, a serviço de um sistema de oposições binárias, promovendo no espectador um efeito tranquilizador, já que ele sempre sabe a que valores deverá aderir. Em outras produções, no entanto, este trabalho pode ser muito mais complexo e ameaçador para o espectador, na medida em que é a própria crise dos valores que é colocada em causa pela mise en phase.

Entre os cognitivistas, a estrutura moral do filme é vista muitas vezes como um determinante essencial para o engajamento do espectador com o personagem (SMITH, 1997). Já Plantinga (2009, p. 191) chama atenção para a "retórica da emoção", ou seja, para as relações entre as estratégias de produção de efeitos emocionais de um filme e sua retórica, o universo de ideias e valores morais que ele transmite e que exercem um impacto persuasivo sobre o espectador. $\mathrm{Na}$ opinião do autor, o apelo às emoções no cinema "não é apenas uma questão de sentimentos, mas diz respeito também a formas de pensar e valorizar que são encorajadas pelo texto e que precedem ou acompanham a resposta emocional. Por estas razões, as emoções do espectador sempre levantam questões éticas e ideológicas"21 (PLANTINGA, 2009, p. 191).

20. Par mise en phase, j'entends le processus qui me conduit à vibrer ao rythme de ce quele filme me donne à voir et à entendre. La mise en phase est une modalité de La participation affective du spectateur au film.

21. The elicitation of emotion is not merely about feelings; it is also about ways of thinking and valuing 
ano 2 número 4

Temáticas

Livres

Neste contexto, é útil indagar acerca das relações entre a retórica de um filme como Epidemic e suas estratégias de apelo afetivo. Ao contrário das produções "B" de terror com que dialoga em sua sequência final, este filme de baixo orçamento está repleto de longas digressões e referências alegóricas orientando o espectador a um tipo de fruição que está longe de centrar-se majoritariamente nos prazeres e desprazeres do corpo e em suas sensações. O próprio contexto de exibição e circulação da obra —lançada durante o Festival de Cannes, uma das principais instâncias de divulgação e reconhecimento do chamado cinema de arte ou autoral - já constrói para o espectador um outro horizonte de expectativas, levando-o a se interrogar sobre as intenções por trás do recurso à afetação, sobre os valores, ideias e reflexões que poderiam justificá-la.

Acontece que há poucas garantias a quem se dedicar à tarefa de identificar o "ponto de vista" deste filme, no sentido aí, obviamente, não da focalização narrativa mas de uma perspectiva sobre as coisas do mundo, sobre os dados da realidade a que a obra se refere. Pistas contraditórias permitem a Epidemic ser compreendido ora como uma alegoria perturbadora sobre a experiência do horror - numa Europa assombrada pelos fantasmas da $2^{\text {a }}$ Guerra Mundial e da Guerra Fria - ora como pura farsa, uma brincadeira provocadora com nossas reações sensório-emocionais, e também com os nossos critérios a cerca do bom e do mau gosto ou daquilo que pode ser considerado "cinema de qualidade".

Para a primeira interpretação, contribuem algumas infor mações extratextuais. Os outros dois filmes da Trilogia Europa - $O$ elemento do crime e Europa se apresentam como reflexões sombrias e esteticamente sofisticadas sobre o continente europeu e seu passado traumático - sobretudo Europa, que narra a história de um norte-americano de ascendência germânica que vai morar na Alemanha após o fim da guerra para auxiliar na reconstrução do país. Além disso, em Epidemic, há um episódio (aparentemente sem muita relação com o restante da história) no qual Lars e Niels decidem fazer uma viagem à Alemanha. Lá encontram um amigo que lhes relata uma revelação feita pela 
mãe em seu leito de morte sobre a experiência terrível que ela viveu no segundo bombardeio inglês em Colônia durante a $2^{\text {a }}$ Guerra, exatamente no dia do seu nascimento ${ }^{22}$.

Em paralelo a ref lexões como estas, os indícios que levam a uma inter pretação de Epidemic enquanto farsa se multiplicam. Muitas delas já foram examinadas aqui, mas vale a pena retornar à questão. Nas cenas do "filme dentro do filme" o efeito farsesco parece ser buscado por uma combinação de estratégias contrastantes. De um lado, há os movimentos solenes de câmera e a música de Richard Wagner - que surge grandiosa e trágica como um leitmotiv, dando um tom épico à narrativa de Dr. Mesmer. Do outro, as situações e diálogos que muitas vezes soam não só inverossímeis como bizarros e de mau gosto. Um dos exemplos mais eloquentes é a cena que mostra o desespero de um padre, companheiro de viagem de Dr. Mesmer, diante da disseminação da epidemia. Flutuando num lago cercado por corpos de outras vítimas da praga, o personagem - que é interpretado por um ator negro - berra a seguinte frase: "Que diabos! Tudo o que um negro precisa são sapatos folgados, xotas apertadas e um lugar quente pra cagar!".

De modo também insólito, após a violência psicológica produzida pela sequência da hipnose, o filme se encerra com os créditos passando sobre movimentadas imagens aéreas de prédios, fábricas e estradas de alta velocidade acompanhadas, na banda sonora, por uma curiosa versão rock'n roll da música de Wagner, com letra escrita por Lars von Trier e Niels Vorsel. No refrão, as palavras de horror que ouvimos na cena anterior reaparecem, agora cantadas animadamente por um corinho: "Epidemic, we all fall down".

Desse modo, o filme se encerra deixando - por meio do recurso à ironia e à farsa - a sugestão de uma intencionalidade da narrativa no sentido de apenas

22. Também nesta cena o filme brinca com referências cruzadas das mais diversas. No relato sobre o bombardeio, o personagem conta que sua mãe teria ficado soterrada, tendo arranhado a parede com as mãos para fazer um buraco e acenar às pessoas, que a ajudaram a sair. Em uma cena do filme dentro do filme - exibida poucos minutos depois - vemos uma mulher soterrada se debatendo por socorro: trata-se da enfermeira, namorada do Dr. Mesmer, que teria sido enterrada viva entre as vítimas da peste. Além disso, o hospital no qual a mãe do personagem estava durante o bombardeio ficava na rua Richard Wagner, enquanto a música do compositor alemão pontua todo o filme. 
ano 2 número 4

Temáticas

Livres

realizar um jogo com os afetos do espectador. É nesse sentido que acreditamos ser coerente dizer que as estratégias de apelo afetivo do filme se apresentam como problemas éticos endereçados a um espectador. Diante da dificuldade de identificar com clareza a retórica do filme, somos desafiados a decidir por nós mesmos acerca do sentido e da legitimidade daquilo que surge em cena como uma mobilização agressiva de reações instintivas básicas.

Este tipo de estratégia pode ser detectada, de forma ainda mais clara, em Dançando no escuro. A história da ingênua imigrante tcheca Selma Jetkova (Björk) - que passa por todo tipo de infortúnio até ser condenada à morte e enforcada nos Estados Unidos dos anos 60 - se apropria de lugares comuns exaustivamente explorados pela dramaturgia para fazer com que o espectador se comova com a personagem, sentindo-se algumas vezes como se estivesse literalmente "na sua pele".

Ao mesmo tempo, o filme deixa revelar, em seus exageros e no descuido em relação ao uso destas mesmas convenções, um subtexto farsesco capaz de fazer com que alguns espectadores se deem conta, com incômodo, das estratégias de apelo afetivo empregadas pela narrativa. Graças a esta configuração é que a obra parece produzir reações emocionais muito discrepantes no público, desde manifestações de intensa comoção e lágrimas a uma franca rejeição não só ao filme como ao seu realizador, acusado não raras vezes de farsante e manipulador (DITZIAN, 2008; GALVÃO, 2011).

\section{Conclusões}

Outros exemplos da filmografia trieriana - como Antichristo (2009) e suas polêmicas imagens de sexo e mutilação genital - poderiam ser elencados aqui para referendar nossas hipóteses, demonstrando o modo como questões relacionadas à participação afetiva do espectador são endereçadas na obra do diretor dinamarquês. Ao elegermos Epidemic como fio condutor da investigação, a intenção foi apenas direcionar um olhar mais atento para um momento particular da trajetória do cineasta, onde parecem ter sido cristalizadas certas estratégias que se tornariam recorrentes na sua produção mais recente e que são de especial interesse para a nossa pesquisa. 
De qualquer forma, espera-se que o exposto neste artigo tenha sido suficiente para demonstrar em que sentido é possível dizer que a obra de Lars von Trier problematiza, a partir de um de um diálogo com as estratégias dos gêneros de corpo, questões éticas e estéticas relacionadas à expressão dos afetos do personagem e à convocação da experiência afetiva do espectador. Obviamente, tais questões não são caras apenas à produção deste cineasta. São problemas que, ainda que não sejam formulados e compreendidos como tais, dizem respeito a todo o campo, orientando soluções na forma de convenções e práticas legitimadas por diferentes tradições nos modos de fazer e pensar cinema.

Nesse sentido, o exercício é parte de um esforço na direção de construir um ponto de vista (ainda que modesto) para o estudo da afetividade nos filmes, centrado em dinâmicas concretas de produção e recepção. Tal ponto de vista permitiria uma apropriação crítica de contribuições teórico-metodológicas distintas (e, os trabalhos de Odin e dos autores cognitivistas aqui citados são apenas alguns exemplos possíveis), por entender que tais abordagens se inserem em uma longa tradição de reflexão sobre o fazer cinematográfico em seu ofício cotidiano de expressar e convocar afetos. Uma reflexão que envolve não só teóricos, mas realizadores, críticos e todos que, de algum modo, experimentam as emoções e sensações proporcionadas pelas imagens em movimento. 


\section{Referências}

ano 2 número 4

Temáticas

Livres

BAINBRIDGE, Caroline. The cinema of Lars von Trier: authenticity and artifice. Wallflower Press: London, 2007.

BARTHES, Roland. "En sortan du cinema”. Communications, 23, 1975. 104-107.

BERTON, Mireille. “ Cinéma et hypnose (Raymond Bellour, le Corps du cinéma : hypnoses, émotions, animalités I Stefan Andriopoulos, Besessene Körper : Körperschaften und die Erfindung des Kinos I Ruggero Eugeni, La relazione d'incanto. Studi su cinema e ipnosi I Rae Beth Gordon, Why the French Love Jerry Lewis : From Cabaret to Early Cinema)", 1895. Mille huit cent quatre-vingt-quinze [En ligne], 58 | 2009, mis en ligne le 01 octobre 2012. Disponível em: http://1895.revues.org/3971. Acessado em 7 de novembro de 2011.

BORNHEIM, Gerd. Brecht: a estética do teatro. Rio de Janeiro: Graal, 1992.

CLOUGH, Patricia; HALLEY, Jean. The affective turn: theorizing the social. Durhan: Duke University Press, 2007.

DELEUZE, Gilles. Cinema 1: Imagem-movimento. São Paulo: Brasiliense, 1983.

. Cinema II: A Imagem-tempo. São Paulo: Brasiliense, 2007.

FURUITI, Edna. A imagem fundamental e o traumático: possibilidades de sentidos em Festa de Família, e na Trilogia Coração de Ouro, de Lars von Trier. 2003. 125 f. Dissertação (Mestrado em Ciências da Comunicação) - Escola de Comunicação e Artes/ Universidade de São Paulo, São Paulo.

JULLIER, Laurent; MARIE, Michel. Lendo as imagens do cinema. São Paulo. Ed. Senac, 2009.

LUMHOLDT, Jan (Org.). Lars von Trier: interviews. EUA: University Press of Mississipi, 2003.

MORIN, Edgar. O cinema ou o homem imaginário. Lisboa: Moraes, 1970.

METZ, Christian. A significação no cinema. São Paulo: Ed. Perspectiva, 1977.

ODIN, Roger. De la fiction. Bruxelles: De Boeck \& Larcier, 2000. 
OLIVEIRA, Fábio Crispim de. Espaços excludentes, corpos excluídos: a narrativa cinematográfica de Lars von Trier. Brasília, 2004. 144 f. Dissertação (Mestrado em Literatura), Universidade de Brasília, Brasília.

PLANTINGA, Carl. "The Scene of Empathy and the Human Face on Film". In: PLANTINGA, Carl R.; SMITH, Greg. Passionate views: Film, cognition and emotion. Baltimore, Maryland: The John Hopkins University Press, 1999.

. Moving viewers: American film and the spectators experience. Los Angeles:

University of Califórnia Press, 2009.

RODRIGUES, Virgínia Jorge Silva. Coração de ouro: o cinema melodramático de Lars von Trier. 2006. 231 f. Dissertação (Mestrado em Comunicação e Cultura Contemporâneas). Faculdade de Comunicação, Universidade Federal da Bahia, Salvador.

SIMONS, Jan. Playing the Waves: Lars von Trier's game cinema. Amsterdam University Press

- Film culture in transition, 2007.

SMITH, Murray. Engaging characters: Fiction, emotion, and the cinema. New York: Oxford University Press, 2004.

STAM, Robert. Introdução à teoria do cinema. Campinas: Papirus, 2003.

WILLIAMS, Linda. Film bodies: gender, genre and excess. Film quarterly, Vol. 44, No. 4. (Summer, 1991), p. 2-13. Disponível em http://links.jstor.org/sici?sici=0015-1386\%28199122\%2944\%3A4\%3C2\%3AFBGGAE\%3E2.0.CO\%3B2-2 